\title{
Long Haired Standard Dachshund
}

National Cancer Institute

\section{Source}

National Cancer Institute. Long Haired Standard Dachshund. NCI Thesaurus. Code C53901.

The Long Haired Standard Dachshund is a long-haired variety of dachshund with a height of up to 9 inches. 